\title{
Detection of Tree Crown from Satellite Imagery using Object Based Image Examination
}

\author{
Sujata R. Kadu, Balaji G. Hogade, Imdad Rizvi
}

\begin{abstract}
Detection and delineation of individual tree mainly depends on high resolution satellite images or LiDAR data. Urban green structure, specially urban trees plays a key role in enhancing the life of people. Now a day's more than half of population is leaving in cities and urban areas. Methods to quantify and monitor trees are not efficient. The traditional methods for forest survey and ground survey are complex because of changes occurs in urban environment. The objective of this research is to extract vegetation using colour based and decision tree method, which can be further sub-classify to obtain area under tree canopy. The results obtained through Object-Based Image Analysis (OBIA) method are also compared with existing Gaussian Mixture Model (GMM) method. The overall accuracy achieved thereby is $93.85 \%$ using Decision tree-multiresolution segmentation and $93.31 \%$ using Decision tree-GMM method.
\end{abstract}

Keywords : object based image analysis, decision tree, colour based segmentation, Gaussian mixture model, multi resolution segmentation.

\section{INTRODUCTION}

The vegetation is the primary factor which affects the environmental conditions. Urban ecosystem depends on accurate mapping and monitoring of vegetation [1]. The lack of fresh water resources increases the water demands. In 2019 , inadequate amount of water affects every continent and it is one of the largest global risks over the next decade [2]. Global risk occurs because of world population, changing consumption pattern and deforestation. Planting trees is one of the efficient methods for increasing the level of ground water. Study shows few plants are helped to increase the ground water level through root system e.g. Ashok tree, Neem tree, Imli tree and Jamun tree etc. Various algorithms have been introduced to map and monitor urban canopy[3]. Different algorithms are available for extraction of urban tree canopy. Segmentation is one of the methods for extraction of urban vegetation [4]. Different models like fuzzy model, water shade model, multi resolution segmentation etc. are used for segmentation. Multiresolution water shade transform based image segmentation has been used, followed by modified CBF which improves classification accuracy [5].

Revised Manuscript Received on September 25, 2019

Sujata R. Kadu, Department of Electronics and Telecommunication Engineering, Terna Engineering College, Navi Mumbai, INDIA

Balaji G. Hogade, Department of Electronics Engineering, Terna Engineering College, Navi Mumbai, INDIA Technology, Sharjah Campus, University City, Sharjah ,UAE,Department of Electronics and Telecommunication Engineering, Terna Engineering College, Navi Mumbai, INDIA
Imdad Rizvi, Electrical Engineering Division, Higher Colleges of

Texture is one of the criteria for extracting information from imagery [6]. There are different methods available [7] but the most popular is statistical approach. In this research objectbased multi resolution method is used for tree mapping. This paper deals with colour based segmentation and decision tree algorithm, for extraction of vegetation. This vegetation further classifies, with the help of multi resolution segmentation to extract the tree canopy. In this research GMM method is also employed to compare with proposed methodology. This paper is organized as follows: section 2 presents propose methodology, section 3 discuss experimental results and discussion. Conclusion follows in section 4 .

\section{PROPOSED METHODOLOGY}

\section{Gaussian Mixture Model:}

In real life, many data sets are modelled by Gaussian distribution, so it is natural to assume that clusters came from different Gaussian distribution. In GMM method, pixel of each image is considered as a random variable. Density function of random variable is a Gaussian mixture [8]. In GMM method most of the data sets are modelled by Gaussian distribution, so most of cluster comes from Gaussian distribution. In this research, GMM model is used with iterative Expectation Maximization (EM) algorithm for extraction of tree canopy.

EM algorithm is used for parameters calculation although there is no any closed form solution. This algorithm has wide applications, which includes automatic speech recognition, data clustering, infectious disease tracking etc. The expected maximum algorithm estimates probability density function, from incomplete data. It also called as an iterative maximum likely hood estimation method to estimate parameters from complex data. The main goal of EM algorithm is to estimate maximum likely hood function with the parameters mean $\left(\mu_{j}\right)$, covariance $\left(\Sigma_{j}\right)$ and mixing coefficient $\left(\Sigma_{j}\right)$

Standard EM algorithm performs following steps [9].

E - Steps: Estimate the value of latent variables.

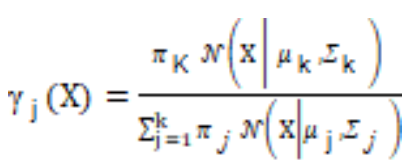

M-Steps: Update the value of parameters.

$$
\mu_{\mathrm{j}}=\frac{\sum_{\mathrm{n}=1 \mathrm{~N}_{\mathrm{j}}}^{\mathrm{N}}\left(\mathrm{x}_{\mathrm{n}}\right) \mathrm{x}_{\mathrm{n}}}{\sum_{\mathrm{n}=1 \mathrm{i}}^{\mathrm{N}} \mathrm{P}_{\mathrm{j}}\left(\mathrm{x}_{\mathrm{n}}\right)}
$$




$$
\Sigma_{j}=\frac{\Sigma_{\mathrm{n}=1 \mathbb{T}_{\mathrm{j}}}^{\mathrm{N}}\left(\mathrm{x}_{\mathrm{n}}\right)\left(\mathrm{x}_{\mathrm{n}}-\mathrm{u}_{\mathrm{j}}\right)\left(\mathrm{x}_{\mathrm{n}}-\mathrm{w}_{\mathrm{j}}\right)^{\mathrm{T}}}{\Sigma_{\mathrm{n}=1 \mathrm{~T}}^{\mathrm{N}}\left(\mathrm{x}_{\mathrm{n}}\right)}
$$

$$
\pi_{j}=\frac{1}{N} \sum_{n=1}^{N} \gamma_{j}\left(x_{n}\right)
$$

Evaluate log-likelihood

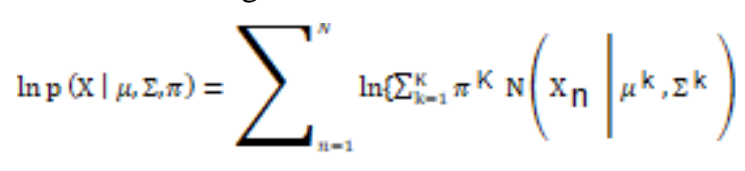

\section{Algorithm:}

Step 1: Initialize the mean, covariance and mixing coefficient

Step 2: $\quad$ Compute the latent variables for all $K$ clusters.

Step 3: Again compute all the parameters using the current values.

Step 4: Compute log-likelihood function. If a log-likelihood function gives the same value then stop, else return to Step 2.

\section{Multi resolution segmentation:}

Image segmentation is the first step in object based image analysis method. It is the process of separating image into non overlapping region. In other words, segmentation is the process of partitioning based on its parameters, such as homogeneity and heterogeneity [10]. There are different image segmentations techniques available [11]. One of the import techniques is region based. Region based technique is based on some regions property, depends on application. This segmentation may refer as spatial clustering. Spatial means pixels in the same category form a single connected component. Clustering means pixel with same values group together to form a cluster [12].

These regions are formed by certain methods like two neighbouring regions that do not have any common property [13-14]. Each region must have uniform conditions, there is overlapping of pixels because each pixel is belongs to single region. Region based segmentation is categorized into two different methods, 'region growing' and 'region merging'.

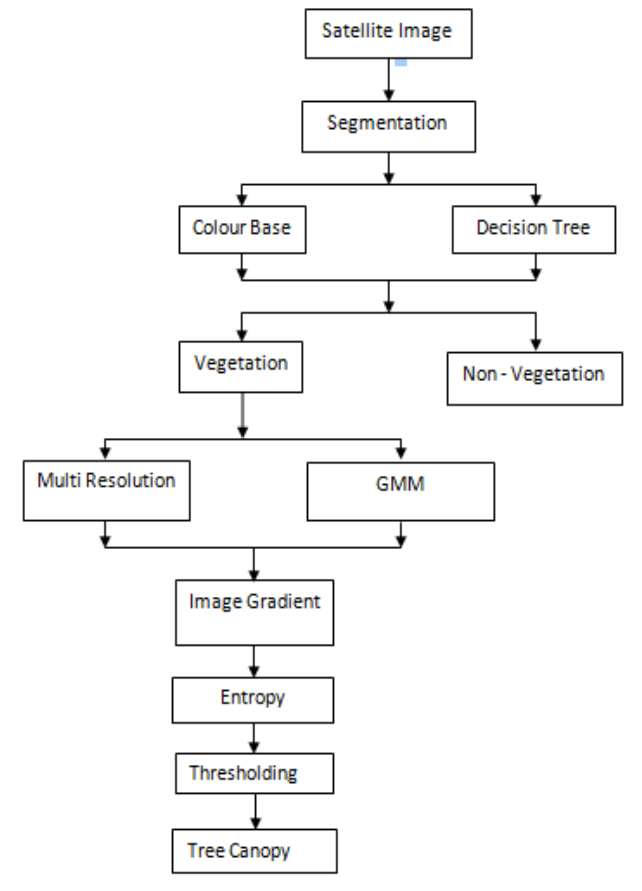

Figure 1. Flowchart for proposed methodology used for UTC extraction

\section{Decision tree classifies:}

A decision tree is a flow chart that divides data into smaller subdivisions on the graphical methods, modelling the decision sequence, simulating random events and results [15]. This method takes binary decision on pixels to place pixels into classes. Here each class is divided into more classes based on their feature selection and defines as many decision nodes as needed. The construction of decision tree classifier does not require any domain knowledge so it is appropriate imagery classification [16]. As mentioned in paper, decision tree classifier gives good accuracy. Decision tree has several advantages over traditional supervise classification procedure using remote sensing such as clustering and maximum likelihood algorithm.

This procedure involves three steps splitting nodes, determining which nodes are terminal nodes and assigning class label to terminal node. Decision tree is a tree where each node represents a feature (attribute), each link (branch) represents a decision (rule) and each leaf represents an outcome. Decision tree is build from training data set which consists of objects each of which is completely describes by set of attributes and class label. Attributes are collection of properties containing all the information about one object. This attributes forms internal node of a decision tree while the values of this attributes represents the branches of a tree. Leaf node represents a class of a classifying attributes. Several methods have been proposed to construct decision tree. This algorithm generally uses the recursive partitioning 
concept and its input required a set of training e.g. a splitting rule and a stopping rule. Decision tree works well for large amount of data with lesser time, they are known for their good performance against larger data sets. Decision tree is one of the fastest ways to identify most significant variables and relation between two or more variables.

\section{RESULTS AND DISCUSSION}

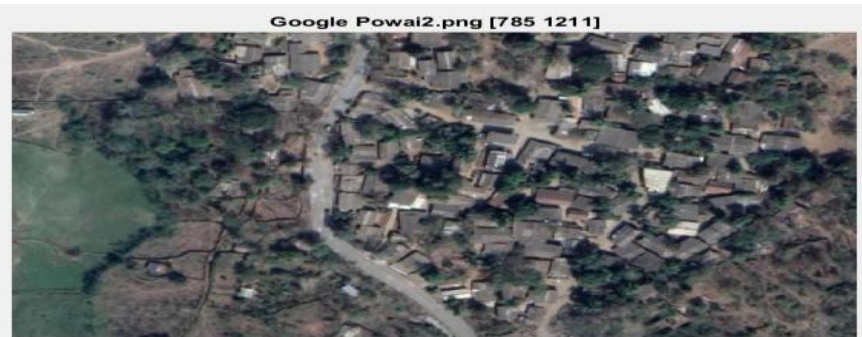

Figure 2. Original Image[17]

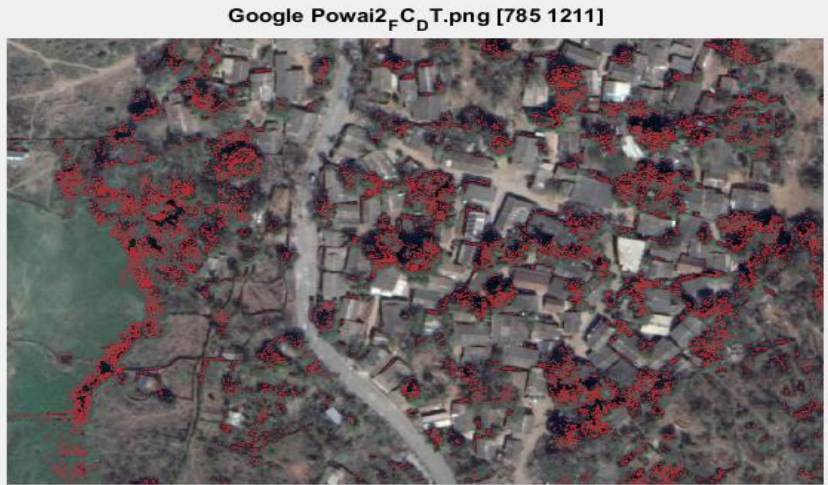

Figure 3. FCC of Original Image

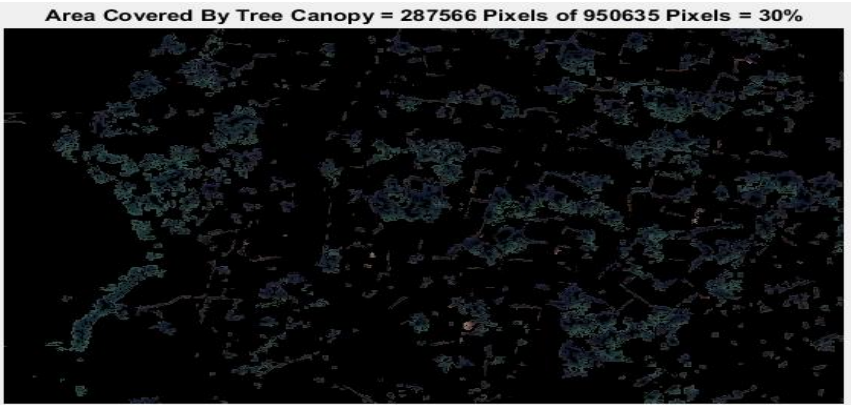

Figure 4. UTC Detection using colour base-GMM

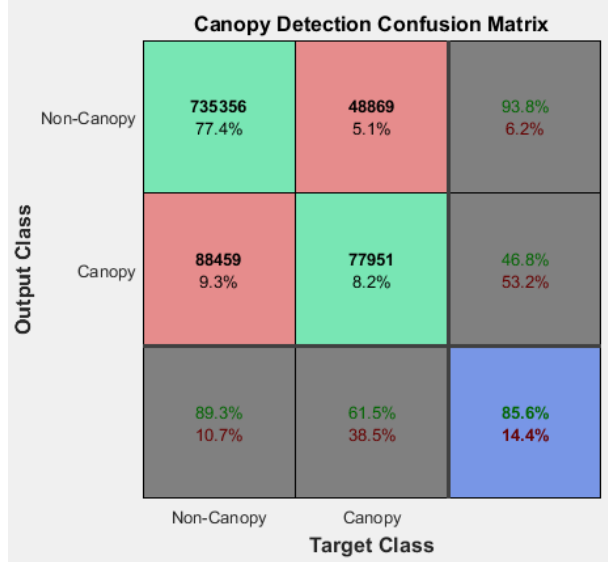

Figure 5. Confusion Matrix

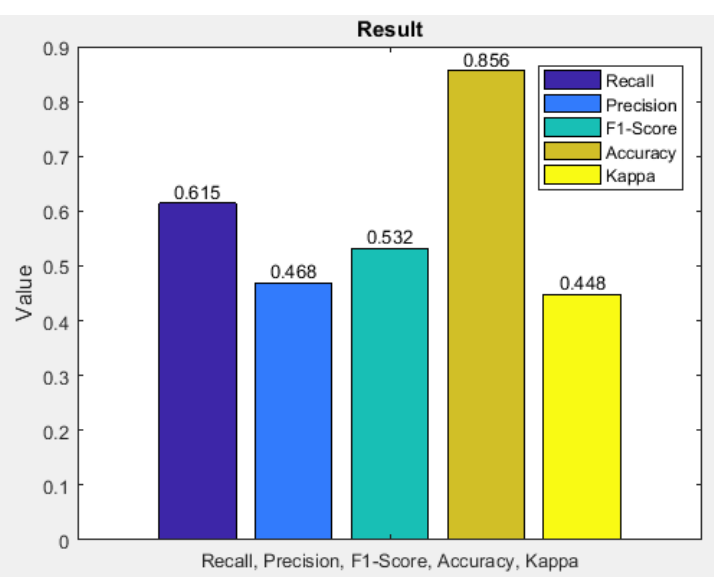

Figure 6. Accuracy and Kappa coefficient

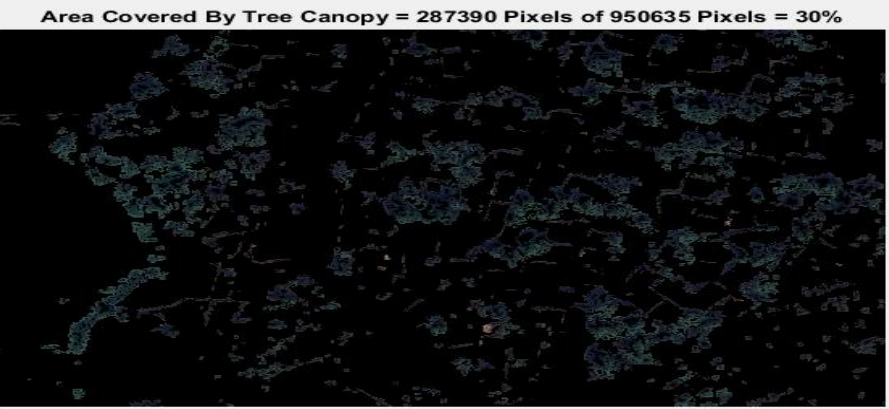

Figure 7. UTC Detection using colour base-multi resolution

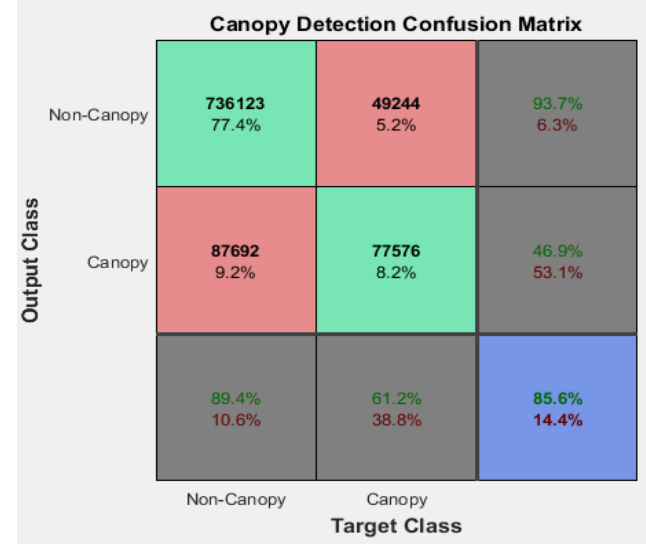

Figure 8. Confusion Matrix

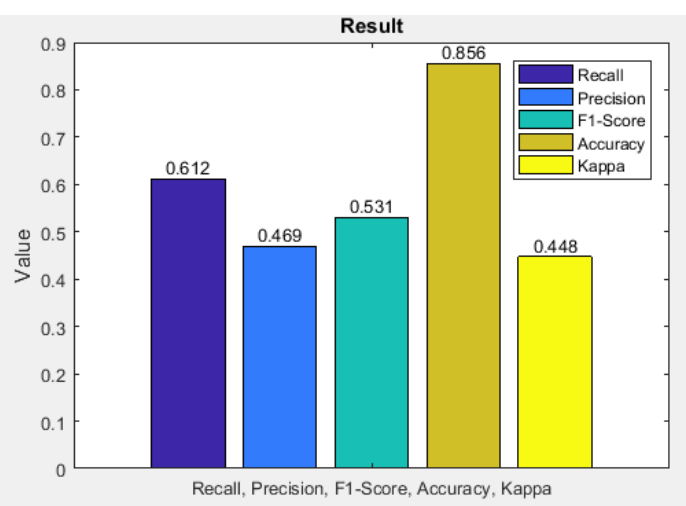

Figure 9. Accuracy and Kappa coefficient 
Table 1. Comparison of Multiresolution and GMM Model with Colour base method

\begin{tabular}{|l|l|l|l|l|l|l|l|l|l|l|}
\hline Parameter/Method' & 'TP' 'TN' & 'FP' & 'FN' & 'FPR' & 'Recall' & $\begin{array}{c}\text { 'Precisio } \\
\text { n' F1-Sco }\end{array}$ & $\begin{array}{l}\text { 'Accura } \\
\text { re' Kappa } \\
\text { cy' } \\
\text { Coeffici } \\
\text { ent }\end{array}$ \\
\hline $\begin{array}{l}\text { Colour } \\
\text { base-multiresolution }\end{array}$ & $\begin{array}{l}7757 \\
6\end{array}$ & 736123 & 87612 & 49244 & 0.1064 & 0.6117 & 0.4694 & 0.5312 & 0.8560 & 0.4578 \\
\hline Colour base-GMM & 7795 & 735356 & 88459 & 48869 & 0.1074 & 0.6147 & 0.4684 & 0.5317 & 0.8555 & 0.4481 \\
& 1 & & & & & & & & & \\
\hline
\end{tabular}

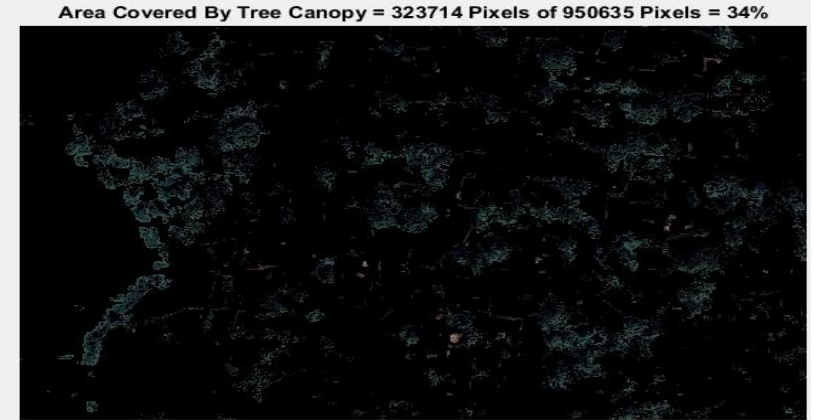

Figure 10. UTC Detection using Decision Tree - GMM model

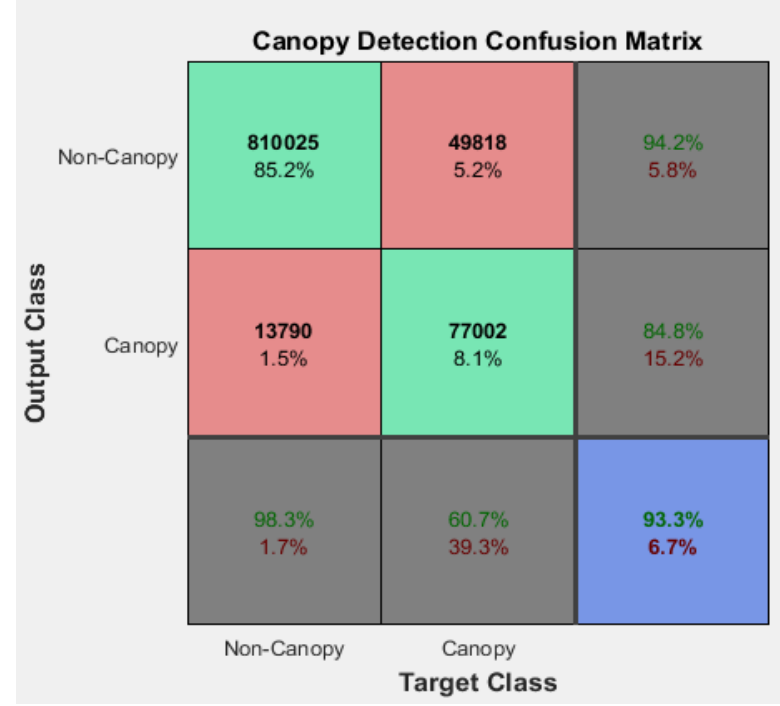

Figure 11. Confusion Matrix

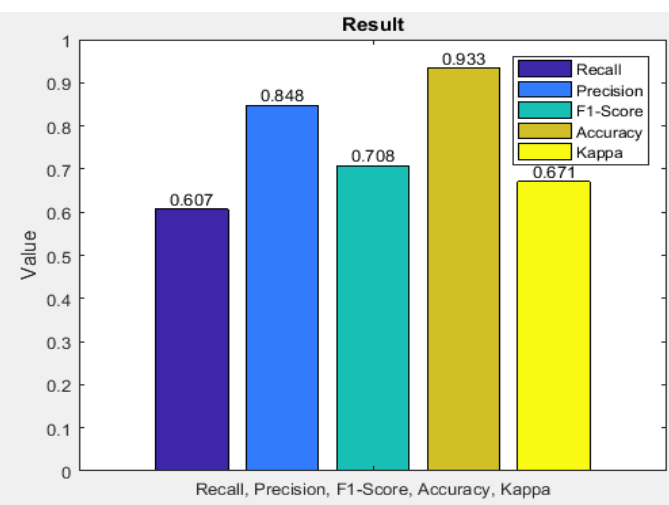

Figure 12. Accuracy and Kappa coefficient

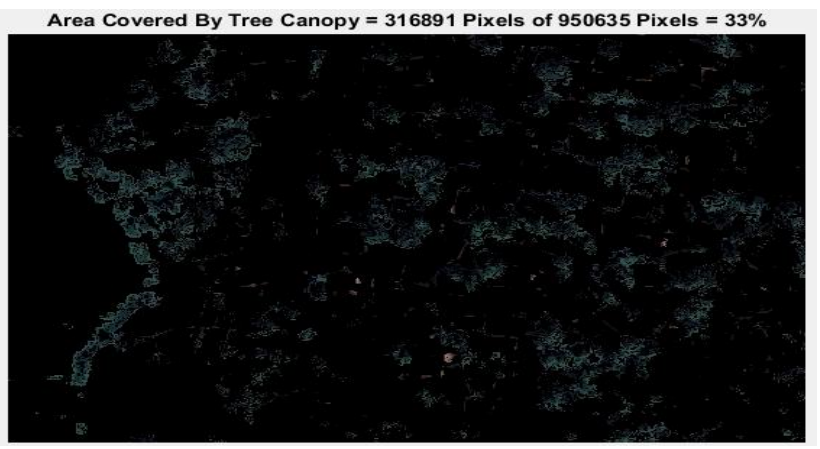

Figure 13. UTC Detection using Decision Tree multiresolution segmentation

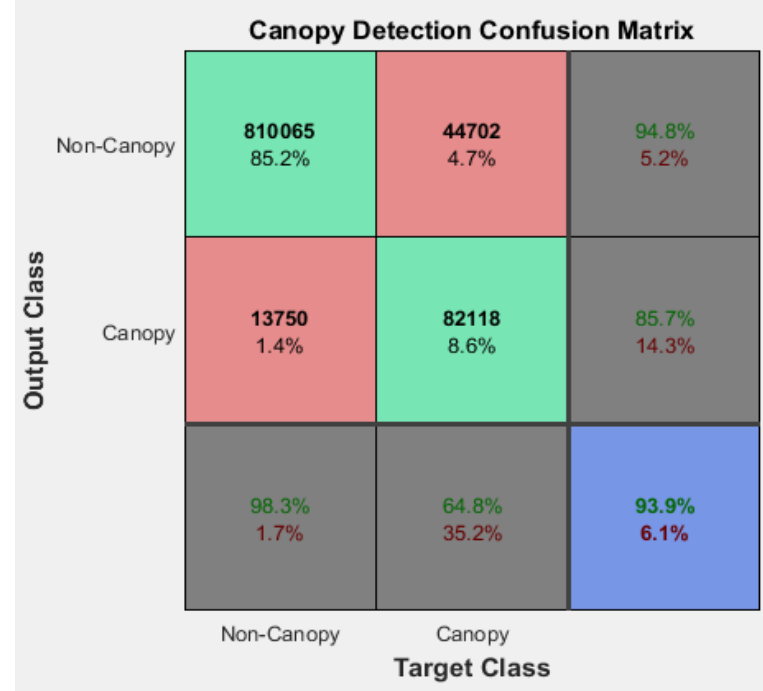

Figure 14. Confusion Matrix

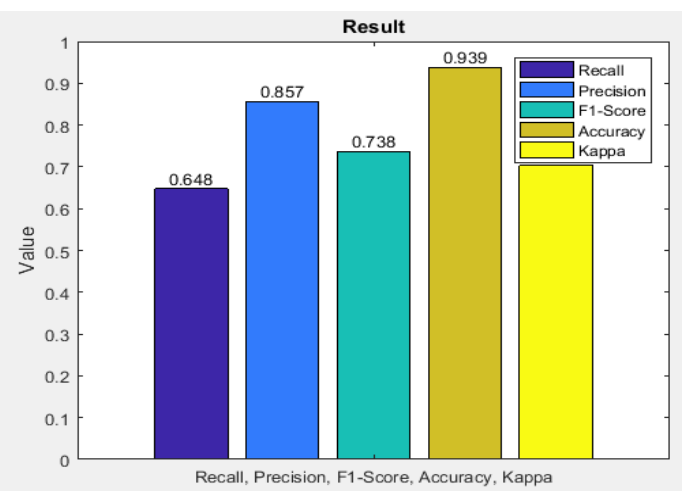

Figure 15. Accuracy and Kappa coefficient

Published By:

Blue Eyes Intelligence Engineering 
Table 2. Comparison of Multiresolution and GMM Model with Decision Tree

\begin{tabular}{|l|l|l|l|l|l|l|l|l|l|l|}
\hline Parameter/Method' 'TP' 'TN' & 'FP' & 'FN' & 'FPR' & 'Recall' & 'Precision' & $\begin{array}{l}\text { 'F1-Sco } \\
\text { re' }\end{array}$ & $\begin{array}{l}\text { 'Accura } \\
\text { cy' }\end{array}$ & $\begin{array}{l}\text { Kappa } \\
\text { Coeffici } \\
\text { ent }\end{array}$ \\
\hline $\begin{array}{l}\text { Decision Tree } \\
\text {-Multiresolution }\end{array}$ & 82062 & 810065 & 13750 & 44758 & 0.0167 & 0.6471 & 0.8565 & 0.7372 & 0.9385 & 0.7031 \\
\hline \begin{tabular}{l} 
Decision Tree-GMM \\
\hline
\end{tabular} & 77002 & 810025 & 13790 & 49818 & 0.0167 & 0.6072 & 0.8481 & 0.7077 & 0.9331 & 0.6711 \\
\hline
\end{tabular}

\section{CONCLUSION}

For the purpose of conducting this research, we consider the Google image of urban area of Powai. Here, vegetation detection using segmentation methods such as colour base and decision tree has been carried out. Subsequently within the area of detected vegetation, area of tree canopy is detected and segmented. The overall accuracy achieved thereby is 93.85\% by Multiresolution Segmentation with Decision tree and $93.31 \%$ using GMM model with Decision tree. LIDAR data gives intensity and height information, so with this data more accurate results can be obtained.

\section{REFERENCES}

1. Corina Iovan, Didier Boldo, Matthieu Cord 'Detection, Characterization, and Modeling Vegetation in Urban Areas From High-Resolution Aerial Imagery' IEEE Journal of Selected Topics in Applied Earth Observations and Remote Sensing. DOI: 10.1109/JSTARS.2008

2. Global risk report 2019, "World economic forum, retrieve 25th March 2019.

3. Walton, J. T., Nowak, D. J., and Greenfield, E. J. 2008. Assessing urban forest canopy cover using airborne or satellite imagery. Arboriculutre and Urban Forestry, Vol. 34, No. 6, pp. 334-340.

4. Saikat Basu, Sangram Ganguly, Ramakrishna R. Nemani, Supratik Mukhopadhyay, Gong Zhang, Cristina Milesi et al., "A semi automated probabilistic framework for tree-cover delineation from 1- $\mathrm{m}$ naip imagery using a high performance computing architecture," IEEE Transactions on Geosciences and Remote Sensing. 53, no 10, 5690-5708 (2018).

5. Imdad Ali Rizvi and B. Krishna Mohan, "Object-oriented method for automatic extraction of road from high resolution satellite images.," Iranian Journal of Earth Sciences. 2, 55-62 (2010).

6. L. Monika Moskal, Diane M. Styers and Meghan Halabisky, "Monitoring urban tree cover using object-based image analysis and public domain remotely sensed data.," Remote Sens. 3, 2243-2262 (2011).

7. Sarika Yadav, Imdad Rizvi, Shailaja Kadam, "Comparative study of object based image analysis on high resolution satellite images for urban development", International Journal of Technical Research and Applications Special Issue 31, PP. 105-110,September 2015.

8. Tang Yinggan, Liu Dong and Guan Xinping, "Multi-resolution image segmentation based on Gaussian mixture model.," Journal of Systems Engineering and Electronics. 17, no 4, 870-874 (2006).

9. Tang Yinggan, Liu Dong and Guan Xinping, "Multi-resolution image segmentation based on Gaussian mixture model.," Journal of Systems Engineering and Electronics. 17, no 4, 870-874 (2006).

10. Baatz, M. and Schäpe, A. "Multiresolution segmentation: an optimization approach for high quality multi-scale image segmentation”. In: XII Angewandte Geographische Informationsverarbeitung, Wichmann-Verlag, Heidelberg, 2000

11. Happ, P. N., Ferreira, R. S., Bentes, C., Costa, G. A .O. P., Feitosa, R. Q., Multiresolution Segmentation: a Parallel Approach for High Resolution Image Segmentation in Multicore Architectures. In: 3rd International Conference on Geographic Object-Based Image Analysis, 2010, Ghent, The International Archives of the Photogrammetry, Remote Sensing and Spatial Information Sciences. Enshede: ITC, 2010. v.XXXVII.

12. M. Saeed,W. C. Karl, T. Q. Nguyen, H. R. Rabiee, "A new multiresolution algorithm for image segmentation.," Proceedings of IEEE International Conference on Acoustics, Speech and Signal Processing, ICASSP. 5, 2753-2756 (1998).
13. Benz U.C., Hofmann P., Willhauc G ; Lingenfelder I., Heynen M," Multi -resolution,object - oriented fuszzy analysis of remote sensing data for GIS-ready information",ISPRSJ.Photogramm 2004,58,239-258. 